\title{
Videos in Teacher Professional Development
}

\author{
Tanya Evans, Leong Yew Hoong and Ho Weng Kin
}

The aim of this Discussion Group was to propose and discuss models of video-based professional development (PD) programmes that are strongly grounded theoretically.

The following presentations were given:

- Kristin Lesseig (Washington State University), "Using videos to support teacher inquiry and noticing".

- Mary Beisiegal (Oregon State University), "To know or not to know? Exploring effects of viewing known and unknown mathematics teachers' instruction."

- Leong Yew Hoong (Nanyang Technological University), "Video-based Unit Study".

- Tanya Evans (University of Auckland) and Greg Oates (University of Tasmania), "The use of videos in professional development of academic staff teaching mathematics at university".

- Heather Lonsdale (Curtin University) and Deborah King (University of Melbourne), "Perception vs reality-using tutorials videos to aid tutor reflection".

- Ho Weng Kin (Nanyang Technological University), "The Impact of Online Video Suite on the Singapore Pre-service Teachers Buying-Into Innovate Teaching of Factorisation via Algecards".

The discussions were framed using the following questions:

T. Evans $(\square)$

University of Auckland, Auckland, New Zealand

e-mail: t.evans@auckland.ac.nz

(C) The Author(s) 2017 
1. Discuss the design of a successful model of video use in PD for mathematics teachers. Provide evidence of its "success". Explicate the role of videos in the PD model.

2. What are existing design principles for successful use of video in PD? What is the connection between these principles and existing theories of teacher learning and of video as teacher learning tool? What cross-countries and cultural differences exist?

3. How can we calibrate a video-based PD model in a way that addresses different emphases of knowledge needs of mathematics teachers along relevant knowledge strands (such as the now well-known domains of Mathematics content knowledge, mathematics pedagogical content knowledge, and knowledge of student learning)?

The discussion group was attended by participants from all around the world which afforded an international perspective on the range of successful video-based PD models for mathematics teachers covering all levels of school and university teaching. During the discussions a request was made by I.K. Rana (Indian Institute of Technology) for access to resources that were mentioned and that can be shared. To that end, a list of contact emails of participants was collected and will be used for sharing resources and future notifications. Contact Tanya Evans t.evans@auckland.ac.nz if you want to be added to this list of researchers with a focus on teacher PD.

Open Access Except where otherwise noted, this chapter is licensed under a Creative Commons Attribution 4.0 International License. To view a copy of this license, visit http://creativecommons. org/licenses/by/4.0/.

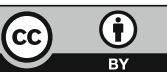

